\title{
Walnut Polyphenols Inhibit Pancreatic Lipase Activity in Vitro and Have Hypolipidemic Effect on High-Fat Diet- Induced Obese Mice
}

\author{
Dandan Shi ${ }^{1}$, Chaoyin Chen ${ }^{1, *}$, Shenglan Zhao ${ }^{2, *}$, Feng Ge $^{1}$, Diqiu Liu ${ }^{1}$, Hao Song ${ }^{1}$ \\ ${ }^{1}$ Faculty of life science, Kunming University of Science and Technology, Kunming, People's Republic of China \\ ${ }^{2}$ Yunnan University of Traditional Chinese Medicine, Kunming, People's Republic of China \\ *Corresponding author: chaoyinchen@163.com; zhaoshenglan@163.com
}

Received September 02, 2014; Revised September 30, 2014; Accepted October 10, 2014

\begin{abstract}
This study was aimed at the chemical composition and inhibitory effects of walnut polyphenols (WP) in vitro lipase activity and on obesity in obese mice models. More than 20 individual phenolics such as gallotannins, ellagitannins, flavonoids and phenolic acids were identified in WP. Studying the interactions between porcine pancreatic lipase (PL) and WP were based on fluorescence quenching and an enzymatic assay. The addition of WP to lipase caused a reduction of protein fluorescence intensity at $310 \mathrm{~K}$. In addtion, we found that the effect of WP on PL was dependent on reaction medium and substrate used and the half maximal inhibitory concentration of WP was determined to be $163 \mu \mathrm{g} / \mathrm{mL}$. At the beginning of the experiment, mice were divided into 3 groups, one of them served as normal control group (NCG), the second as hyperlipidemia control group (HCG), the last as walnut polyphenol-treated group (WTG). After 8 weeks of treatment, we investigated the effects of WP on weight gain, food intake and biochemical indexes in obese mice. The results showed that WP could significantly decrease body weight in obese mice $(-13.52 \%, \mathrm{P}<0.05)$. However, there was no remarkable difference in food intake among three groups (1760.2-1823.3 g). In addition, WP could significantly decrease the TG, TC and LDL-cholesterol (LDL-C) concentrations and increase the HDL-cholesterol (HDL-C) concentration when compared to the HCG (-36.12\%, $31.27 \%,-73.3 \%$, and $+59.72 \%$, respectively, $\mathrm{P}<0.01$ ). The levels of hepatic TG and TC were significantly decrease in WTG when compared to the HCG $(-27.72 \%$ and $-48.43 \%$, respectively, $\mathrm{P}<0.01)$. In conclusion, these results suggest that WP could be a potentially therapeutic alternative in the treatment of obesity caused by a high-fat diet.
\end{abstract}

Keywords: walnut polyphenols, lipase, fluorescence quenching, obese mice

Cite This Article: Dandan Shi, Chaoyin Chen, Shenglan Zhao, Feng Ge, Diqiu Liu, and Hao Song, "Walnut Polyphenols Inhibit Pancreatic Lipase Activity in Vitro and Have Hypolipidemic Effect on High-Fat DietInduced Obese Mice.” Journal of Food and Nutrition Research, vol. 2, no. 10 (2014): 757-763. doi: 10.12691/jfnr-2-10-16.

\section{Introduction}

Obesity is a major health problem worldwide and is now classically characterized by a cluster of several metabolic disorders [1]. Obesity is caused by the results of an imbalance between energy intake and expenditure [2]. A recent study has found that suppression of food intake, stimulation of energy expenditure and lipase inhibition are the main therapies for obesity [3].

Lipases are important enzymes for lipid absorption and secreted by the pancreas, play a vital role in the efficient digestion of triglycerides [4]. PL is a key lipase, responsible for the hydrolysis of $50-70 \%$ total dietary fats [5]. PL inhibition is one of the most widely researched mechanisms used to determine the potential effect of natural products as antiobesity drugs $[6,7,8]$. Orlistat, one of two clinically approved drugs for obesity treatment, is used for inhibiting PL [9]. Although it has good effect on treating obesity, long-term use may cause some side effects such as oily stools, oily spotting and so on. At present, the potential of natural products for the treatment of obesity has become a hot research topic. Some results have been reported that polyphenol or some flavonoids are pancreatic lipase inhibitors $[10,11,12]$.

Walnuts are one of the most popular nuts in the world and contain large amounts of bioactive substances such as polyphenol, polysaccharide, protein and so on. Polyphenols are well-known antioxidants with protective effects against cardiovascular disease, cancer, and other degenerative conditions associated with inflammation [13]. In addition, it has been reported that polyphenols can inhibit pancreatic lipase and thereby influence fat digestion and energy intake [14]. Although the inhibitory effects of some polyphenols on PL have been investigated $[15,16,17]$, this is the first report on the inhibitory activity of WP against PL. So, this paper aimed to quantify the inhibition of PL in vitro by WP, as well as to determine the preventive effects of WP on the development of obesity in mice fed a high-fat diet. 


\section{Materials and Methods}

\subsection{Materials}

Walnut samples were collected at Kunming and porcine pancreatic lipase was from Sigma Chemical (St. Louis, MO). A working solution was prepared with $100 \mathrm{mM}$ Tris-HCl ( $\mathrm{pH}$ 8.2). Triton X-100 and triolein were purchased from Sangon Biotech. p-nitrophenyl laurate (pNP laurate) was purchased form Aladdin Reagent (Shanghai). All the reagents were analytical or of chromatographic purity. Water was ultrapure water.

\subsection{Extraction of Walnut and Determination of Total Polyphenol Content}

Walnut polyphenols were prepared as follows: dried walnut testa was powdered and extracted at $60^{\circ} \mathrm{C}$ for $1 \mathrm{~h}$ with $50 \%(\mathrm{v} / \mathrm{v})$ ethanol (solid-liquid ratio, 1:10), the solvent was subsequently evaporated. Then, the concentrates were formulated as $20 \mathrm{mg} / \mathrm{g}$ solution.

The total polyphenol content in walnut extracts was determined by Folin-Ciocalteu colorimetric method according to Ainsworth and Gillespie [18] with minor modifications. Briefly, extract $(1.0 \mathrm{~mL})$ was mixed with $5.0 \mathrm{~mL}$ of the Folin-Ciocalteu reagent $(1: 10)$ and $4.0 \mathrm{~mL}$ of $\mathrm{Na}_{2} \mathrm{CO}_{3}$ (7.5\% aqueous solution). The absorption was measured at $765 \mathrm{~nm}$ in an Ultrospec 2100 spectrophotometer (UV-Vis, Amersham Biosciences) after $1 \mathrm{~h}$ of incubation at room temperature and in the dark. A standard curve was generated with gallic acid standard substance (concentration ranged from 10 to $70 \mu \mathrm{g} / \mathrm{mL}$ ). The calibration curve equation was $\mathrm{y}=0.1062 \mathrm{x}+0.0144$ and had a correlation coefficient of R2 $=0.9991$. WP were evaluated at a final concentration of $420 \mathrm{mg} / \mathrm{g}$. The total phenolic contents were expressed as percentages (\%) or milligrams per gram (gallic acid equivalents).

\subsection{LC- MS Analysis}

Quantitative analysis of walnut extracts were carried out in an Accela HPLC system from Thermo Fisher Scientific (San Jose, CA, USA) with a G1314A UV detector and a reversed-phase column Atlantis T3 C18 $(100 \times 2.1 \mathrm{~mm}, 3 \mu \mathrm{m})$. Mobile phase A and B were respectively, $0.1 \%$ formic acid in water and $0.1 \%$ formic acid in acetonitrile. The extract $(10 \mu \mathrm{L})$ was separated at $20^{\circ} \mathrm{C}$ at a flow rate of $350 \mu \mathrm{L} / \mathrm{min}$ using the following eluents with the linear gradient mode: The 33 min gradient method began with $100 \%$ A in 1 min, $100-92 \%$ in $3 \mathrm{~min}$, $92-80 \% \mathrm{~A}$ in $20 \mathrm{~min}, 80-70 \%$ A over $2 \mathrm{~min}, 70-0 \% \mathrm{~A}$ over 2 min and finally $100 \%$ B for 5 min.

Mass spectra were obtained from Thermo Fisher Scientific (San Jose, CA, USA) with an electrospray ionization source and ion trap detector operated in negative ion mode. Instrument control and data acquisition were run on Xcalibur Data Analysis 2.0.7 software [19].

\subsection{Fluorescence Spectra}

Fluorescence measurements were conducted on a spectrofluorimeter model LS-50 (PerkinElmer, USA) spectrometer. Briefly, appropriate quantities of WP solution were transferred to a $10 \mathrm{ml}$ tube, then $1.0 \mathrm{ml}$ of $0.5 \mathrm{mg} / \mathrm{ml}$ lipase solution was added, and the solution was diluted to $10 \mathrm{ml}$ with Tris buffer and incubated at $37^{\circ} \mathrm{C}$ for $30 \mathrm{~min}$, then, the mixtures were centrifuged at $7000 \mathrm{rpm}$ for $10 \mathrm{~min}$ and the supernate was injected in $1.0 \mathrm{~cm}$ quartz cells. Scanning parameters for all measurements were optimized with slit width $10.0 \mathrm{~nm}$ for excitation and emission. The excitation wavelength was $295 \mathrm{~nm}$, and the emission spectra was recorded in the wavelength range of $310-450 \mathrm{~nm}$ at a scan rate of $300 \mathrm{~nm} / \mathrm{min}$ and the resolution was $1.0 \mathrm{~nm}[6,20]$.

\subsection{Lipase Activity Assay}

Lipase activity was evaluated by the hydrolysis of pNP laurate spectrophotometrically recorded at $400 \mathrm{~nm}$. Lipase from porcine pancreas was dissolved in ultrapure water at $10 \mathrm{mg} / \mathrm{ml}$ and the supernate was used after centrifugation at $8000 \mathrm{rpm}$ for $10 \mathrm{~min}$. The assay buffer was $100 \mathrm{mM}$ Tris-HCl ( $\mathrm{pH}$ 8.2) and pNP laurate was used as the substrate. The substrate solution was prepared through dissolving pNP laurate $(0.08 \% \mathrm{w} / \mathrm{v})$ in $5 \mathrm{mM}$ sodium acetate buffer ( $\mathrm{pH} 5.0$ ) containing 1\% Triton X-100 and was heated in boiling water for $1 \mathrm{~min}$ to aid dissolution, then cooled to room temperature. The assay was carried out in a total volume of $1000 \mu \mathrm{l}$ containing $300 \mu \mathrm{l}$ TrisHCl buffer, $450 \mu \mathrm{l}$ substrate solution, $100 \mu \mathrm{l}$ of WP with different concentrations and $150 \mu \mathrm{l}$ lipase. The blank assay contained $400 \mu \mathrm{l}$ assay buffer, $450 \mu \mathrm{l}$ substrate solution and $150 \mu$ lipase. After mixing with WP, lipase and substrate solution, the mixtures were incubated at $37^{\circ} \mathrm{C}$ for $30 \mathrm{~min}$ and heated in a boiling water bath for 10 min to stop the reaction. Then the mixtures were centrifuged at $8000 \mathrm{rpm}$ for $10 \mathrm{~min}$ and read at $400 \mathrm{~nm}$ against the blank in a UV-visible spectrophotometer [21].

\subsection{Preparation of High Fat Diet (HFD)}

The HFD was prepared according to the following method: it includes $83.25 \%$ standard diet [22], 10\% lard, 1.5\% cholesterol, 0.2\% NaTDC, 5\% Sugar and 0.05\% Propylthiouracil [23]. The compositions of the experimental diets are shown in Table 1.

Table 1. Composition of the experimental diets

\begin{tabular}{ccccc}
\hline \multirow{2}{*}{ Components } & \multicolumn{2}{c}{ Standard diet } & \multicolumn{2}{c}{ High-fat diet } \\
\cline { 2 - 5 } & $\mathrm{g} / \mathrm{kg}$ & $\mathrm{kcal} / \mathrm{kg}$ & $\mathrm{g} / \mathrm{kg}$ & $\mathrm{kcal} / \mathrm{kg}$ \\
\hline Cornstarch & 400 & 1600 & 333 & 1332 \\
Sucrose & 100 & 400 & 133 & 532 \\
Dextrinated starch & 140 & 560 & 116.5 & 466 \\
Lard & - & - & 100 & 900 \\
Cholesterol & - & - & 15 & 450 \\
Casein & 200 & 800 & 167 & 668 \\
Soy oil & 70 & 630 & 58 & 522 \\
NaTDC & - & - & 2 & - \\
Propylthiouracil & - & - & 0.5 & - \\
Mineral mix & 30 & - & 25 & - \\
Vitamin mix & 10 & - & 8 & - \\
Cellulose & 50 & - & 42 & - \\
Total & 1000 & 3990 & 1000 & 4870 \\
\hline “-”: it represents absence. & & & &
\end{tabular}

\subsection{Animals and Treatments}

This study was conducted according to Kirin Pharmaceutical's guidelines for ethical animal care, handling and termination. Animal experiments were 
carried out in compliance with the standards for use of laboratory animals. After a 2-week adaptation period, animals were randomly divided into 3 groups. One of them served as normal control group (NCG) [24,25]: kept on standard diet and daily gavaged with normal saline. The second as hypercholesterolemia control group (HCG): received HFD and daily gavaged with normal saline. The third as WP-treated group (WTG): received HFD and daily gavaged with WP at a dose of $200 \mu \mathrm{g} / \mathrm{g}$ body weight for 8 weeks. The average food intake by each group and the body weight by each mouse were measured once weekly.

\subsection{Biochemical Analysis}

The serum was obtained by centrifugation of the blood at $3000 \mathrm{rpm}$ for $15 \mathrm{~min}$ and the total cholesterol (TC), total triglycerides (TG), and HDL-C concentrations were immediately determined using the corresponding diagnostic kits (Nanjing Jiancheng Bioengineering Institute, Nanjing, PR China). The LDL-C was calculated by the Friedwald formula [26]: LDL-C = TC - [HDL-C + (TG/5)]. To determine liver total cholesterol (TC) and triglycerides (TG), one gram of liver from each mouse was homogenized in $10 \mathrm{~mL}$ isopropanol. The homogenate was allowed to stand for $48 \mathrm{~h}$ at $4^{\circ} \mathrm{C}$. The mixture was centrifuged $10 \mathrm{~min}$ at $2500 \mathrm{~g}$ and the supernate was used for lipid analysis. TC and TG were determined using reagent kits as described above.

\subsection{Statistical Analysis}

Statistical analysis was performed with the use of SPSS software (version 19.0, Chicago, IL, USA). Results are expressed as mean \pm SD. The statistical significance of experimental observations was determined by one-way ANOVA. Statistical significance was set at $\mathrm{P}<0.05$.

\section{Results}

\subsection{Identification of Phenolic Compounds in WP}

WP were found to contain a highly complex mixture of gallotannins, ellagitannins, flavonoids and phenolic acids; more than 20 individual phenolics were identified. Corresponding molecular formulas, their retention time (tR) and their molecular mass were shown in Table 2. In addition, many of identified phenolic compounds were found along the chromatogram (Figure 1).

Table 2. Phenolic compounds were identified in WP

\begin{tabular}{|c|c|c|c|c|}
\hline Number & $\mathrm{tR}(\min )$ & Compound identification & Formula & Measured mass \\
\hline 1 & 2.66 & HHDP-glucose isomer & C20H18O14 & 482.07 \\
\hline 2 & 2.84 & Vanillic acid & С8H8O4 & 168.15 \\
\hline 3 & 3.16 & HHDP-glucose isomer & C20H18O14 & 482.07 \\
\hline 4 & 3.25 & Pyrogallic acid & C6H6O3 & 126.11 \\
\hline 5 & 3.26 & Gallic acid & C7H6O5 & 170.02 \\
\hline 6 & 4.47 & HHDP-glucose isomer & C20H18O14 & 482.07 \\
\hline 7 & 5.92 & Neochlorogenic acid & C16H18O9 & 354.31 \\
\hline 8 & 7.07 & Pedunculagin/casuariin Isomer & С34H24O22 & 784.07 \\
\hline 9 & 8.22 & Chlorogenic acid & C16H18O9 & 354.31 \\
\hline 10 & 9.72 & Pedunculagin/casuariin Isomer & С34H24O22 & 784.07 \\
\hline 11 & 13.62 & Salidroside & C14H20O7 & 300.30 \\
\hline 12 & 15.25 & (-)-epicatechin & C15H14O6 & 290.08 \\
\hline 13 & 20.14 & Ferulic acid & C10H10O4 & 194.19 \\
\hline 14 & 20.57 & (-)-epicatechin-3-O-gallate & C22H18O10 & 442.09 \\
\hline 15 & 22.24 & 3-p-coumaroylquinic acid & C16H18O8 & 338.10 \\
\hline 16 & 23.47 & 4-p-coumaroylquinic acid & C16H18O8 & 338.10 \\
\hline 17 & 23.47 & Ellagic acid hexoside isomer & C21H20O12 & 464.09 \\
\hline 18 & 25.02 & Ellagic acid pentoside isomer & C20H18O11 & 434.08 \\
\hline 19 & 26.11 & Ellagic acid & C14H6O8 & 302.01 \\
\hline 20 & 28.61 & Caffeic acid & С9H8O4 & 180.15 \\
\hline 21 & 28.91 & Coumaric acid hexoside isomer & C15H18O8 & 326.01 \\
\hline 22 & 29.52 & Ellagic acid hexoside isomer & C21H20O12 & 464.09 \\
\hline
\end{tabular}

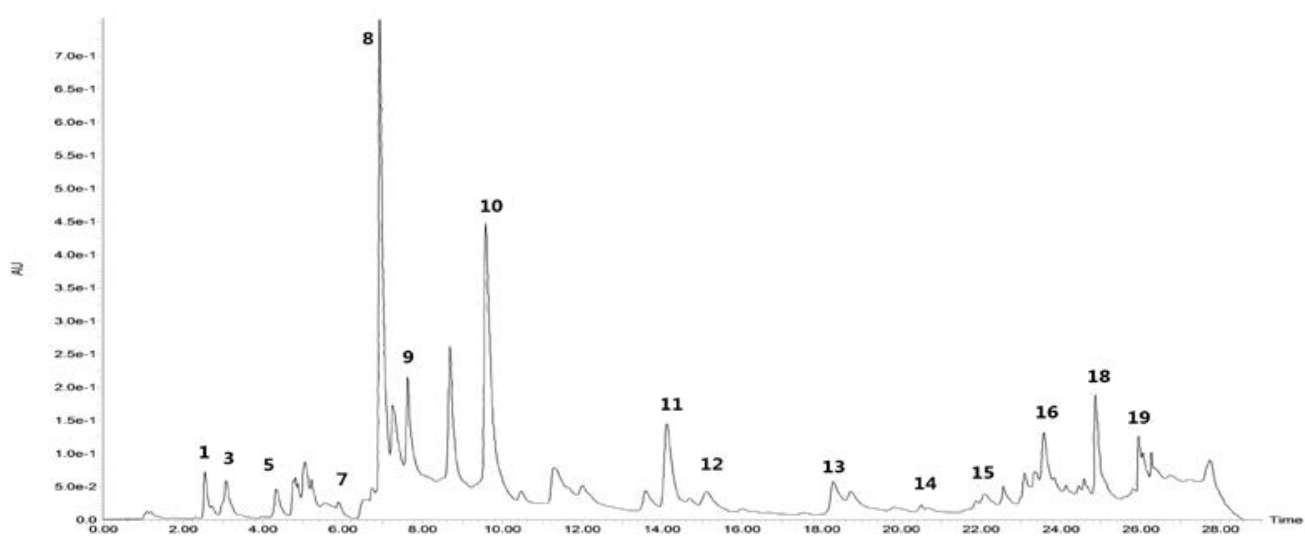

Figure 1. Chromatographic profile obtained at $280 \mathrm{~nm}$ for WP. Peak number identities are displayed in Table 2 


\subsection{Fluorescence Quenching}

The fluorescence intensity of lipase decreased at 350 $\mathrm{nm}$ for WP-PL systems (Figure 2). Thus, walnut polyphenols bound with lipase caused microenvironment changes. The observed $\lambda_{\mathrm{em}}$ for lipase $\left(\lambda_{\mathrm{em}}=350 \mathrm{~nm}\right)$ is higher that the $\lambda_{\text {em }}$ for lipase for the isolate indole group of $\operatorname{Trp}\left(\lambda_{\mathrm{em}}=356.5 \mathrm{~nm}\right)$.

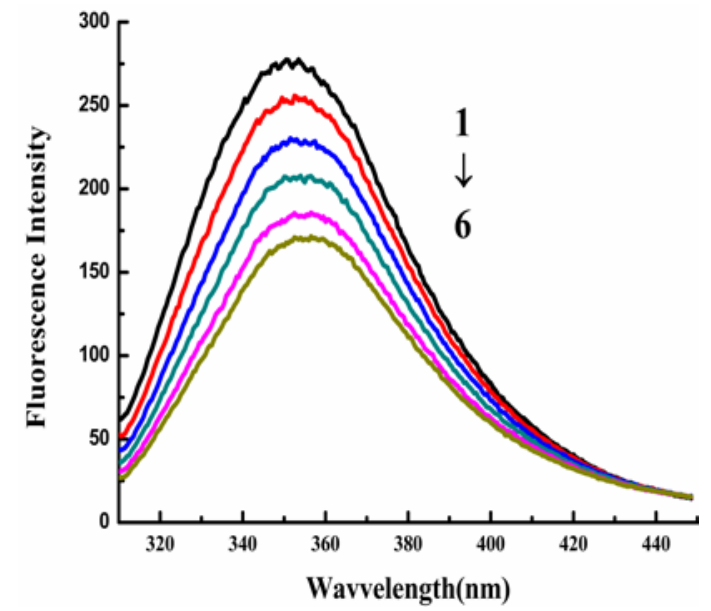

Figure 2. The quenching effect of WP on lipase fluorescence intensity at $37^{\circ} \mathrm{C}$ and $\mathrm{pH} 8.2$. $\lambda$ ex $=295 \mathrm{~nm}$. (1-6) with $1.0 \times 10^{-5} \mathrm{M}$ lipase. $1 \rightarrow 6$ : WP concentration increased from $10 \mu \mathrm{g} / \mathrm{mL}$ to $60 \mu \mathrm{g} / \mathrm{mL}$

\subsection{Inhibition of Lipase Activity by WP}

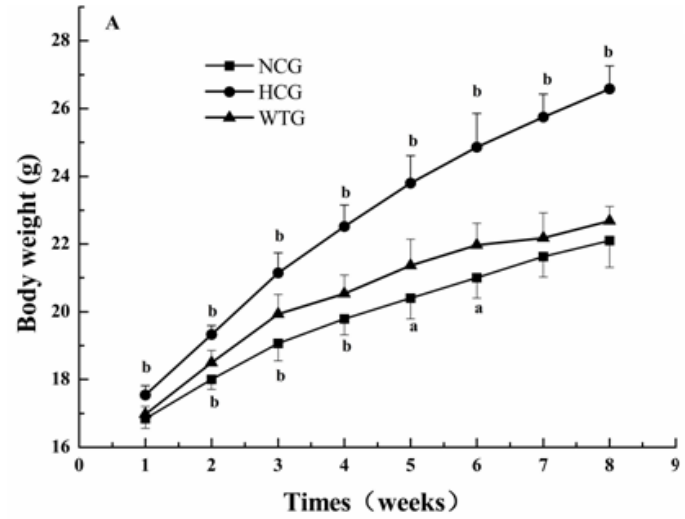

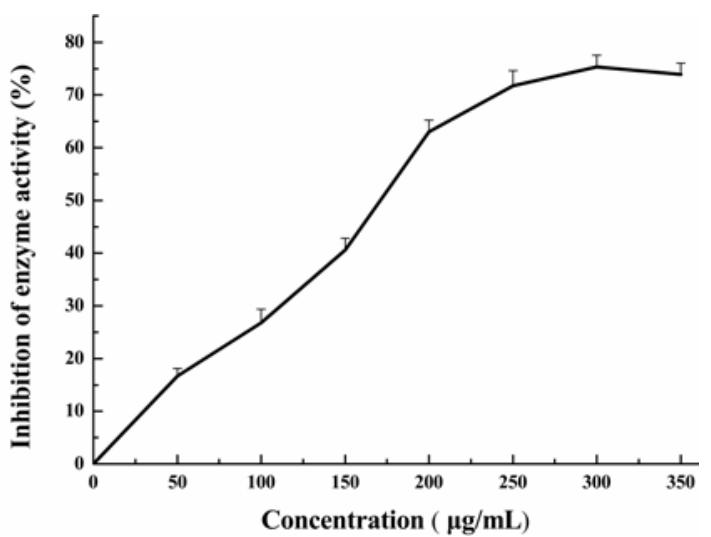

Figure 3. Effect of WP on porcine pancreatic lipase activity in vitro. WP concentration increased from $0 \mu \mathrm{g} / \mathrm{mL}$ to $350 \mu \mathrm{g} / \mathrm{mL}$. The data are given as mean $\pm \mathrm{SD}(\mathrm{n}=3)$

The inhibition effects of WP against porcine pancreatic lipase were determined by using different concentrations of WP (50-350 $\mu \mathrm{g} / \mathrm{mL})$ (Figure 3). WP inhibited the enzyme activity in a dose-dependent way and its suppressive effects against lipase reached maximum at $300 \mu \mathrm{g} / \mathrm{ml}$ (75.36\% inhibition). The half maximal inhibitory concentration of WP was determined to be 163 $\mu \mathrm{g} / \mathrm{mL}$.

\subsection{Effects of WP on Weight Gain, Food Intake in Obese Mice}

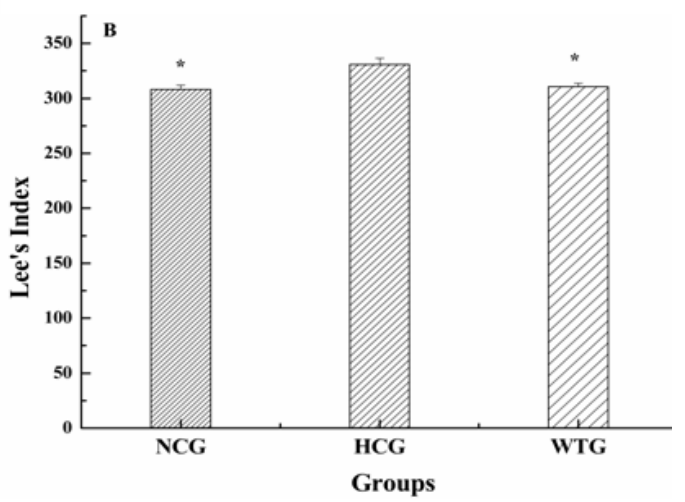

Figure 4. Effects of WP on body weight gain and Lee's index in mice fed high-fat diet for 8 weeks. (A) Body weights (g) of mice (mean \pm SD) consuming the indicated diets for the 8-week intervention period. Significant difference between groups for each week is signified by letter a and b, a was represented as ${ }^{*} \mathrm{p}<0.05$, b was represented as $* * \mathrm{p}<0.01$. (B) Lee's index of mice on indicated diets during the intervention period. Results are expressed as mean $\pm \mathrm{SD}$ of nine animals per group, ${ }^{*} \mathrm{p}<0.05$

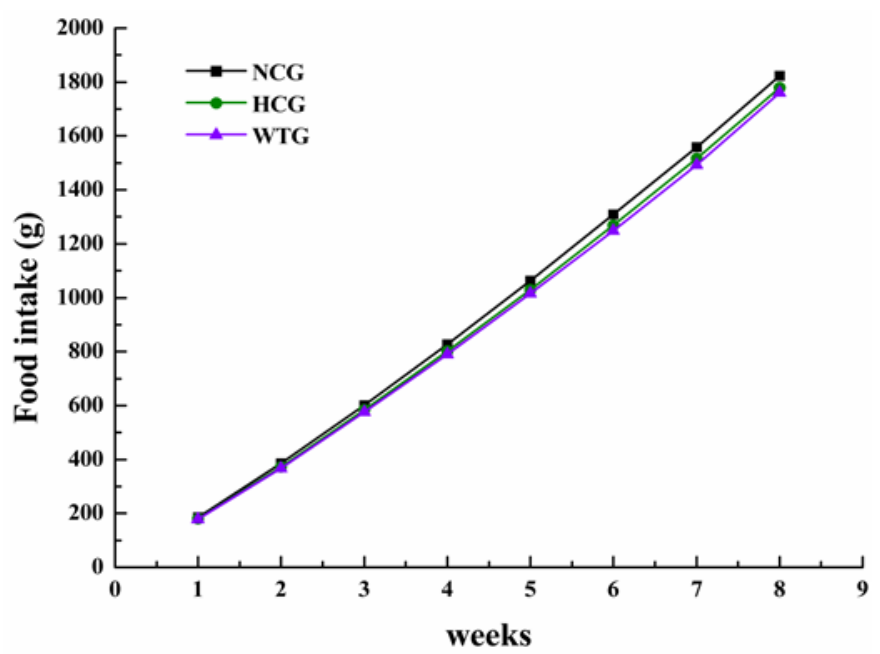

Figure 5. Effects of WP on food intake in mice fed high-fat diet for 8 weeks. Results are expressed as mean \pm SD of nine animals per group 
The body weight gain in mice fed a high-fat diet containing WP was reduced by $13.52 \%$ compared to mice fed a HFD as shown in Figure 4A. In the case of HFD, the body weight gain was increased by $20.18 \%$ compared to mice fed a standard diet. As shown in Figure 4B, there were also significant changes in Lee's index (308.03330.76) among there groups. On the other hand, there was no remarkably difference in food intake (1760.2-1823.3 g) in Figure 5.

Table 3. Effects of WP on serum parameters and liver lipids

\begin{tabular}{cccc}
\hline \multirow{2}{*}{ Groups } & \multicolumn{2}{c}{ Serum lipids (mmol/L) } \\
\cline { 2 - 4 } NCG & TG & TC & HDL-C \\
HCG & $1.55 \pm 0.04$ & $1.72 \pm 0.11$ & $1.3 \pm 0.06$ \\
WTG & $0.99 \pm 0.08$ & $2.75 \pm 0.11^{* *}$ & $0.72 \pm 0.08^{* *}$ \\
\hline Values were measured after 8 wk for feeding. Date are means \pm SD for 9 mic \\
3.5. Effects of WP on serum parameters and \\
liver lipids
\end{tabular}

The serum lipid profile was significantly increase in HCG with respect to NCG. As shown in Table 3, TG and TC levels in HCG were significantly higher than that in NCG after 8-week treatment $(+80.23 \%$ and $+59.88 \%$, respectively, $\mathrm{P}<0.01)$. the LDL-C level was significantly decrease in NCG $(-78.41 \%, \mathrm{P}<0.01)$ and the HDL-C level was significantly increase in NCG with respect to HCG $(+80.56 \%, \mathrm{P}<0.01)$. In addition, the levels of hepatic TG and TC were significantly decrease in NCG when compared to the HCG $(-40.61 \%$ and $-52.25 \%$, respectively, $\mathrm{P}<0.01$ ).

As shown in Table 3, WP significantly decreased the TG, TC and LDL-C concentrations and increased the HDL-C concentration when compared to the HCG ( $36.12 \%,-31.27 \%,-73.3 \%$, and $+59.72 \%$, respectively, $\mathrm{P}<$ 0.01). In addition, the levels of hepatic TG and TC were significantly decrease in WTG when compared to the HCG (-27.72\% and -48.43\%, respectively, $\mathrm{P}<0.01)$.

\section{Discussion}

In this study, a total of 22 phenolic compounds, including gallotannins, ellagitannins, flavonoids and phenolic acids, were identified in walnut polyphenols. The LC/MS spectra were compared with those of candidate compounds found in previous report, especially when the presence of the compound was reported in walnut polyphenols [19,27].

Porcine lipase is the most important enzyme for the efficient digestion of triglycerides. Dietary triglycerides are hydrolyzed by pancreatic lipase to monoglycerides, free fatty acids and other small molecules, which will resynthesize triglycerides in the intestine for the person of food intake leading to obesity. So, inhibiting lipase in the digestive organs is an effective way to prevent the development of obesity [28]. PL has 7 tryptophan (Trp) residues, and the fluorescence of lipase is mainly dominated by Trp emission. When some molecules interact with PL, Trp fluorescence may change depending on the impact of the interaction on the protein conformation $[29,30]$. In this paper, the addition of WP to lipase caused a reduction of protein fluorescence intensity known as quenching effect, it meant that the interaction between PL and WP changed the microenvironment of Trp residues. The emission band of free lipase at $350 \mathrm{~nm}$ shifted toward $356.5 \mathrm{~nm}$, which was related to more exposure of Trp residues and an unfolding protein structure [31,32,33].

\begin{tabular}{ccc} 
& \multicolumn{2}{c}{ Liver lipids (mg/g) } \\
LDL-C & TG & TC \\
$0.38 \pm 0.07$ & $17.27 \pm 1.45$ & $4.88 \pm 0.42$ \\
$1.76 \pm 0.13^{* *}$ & $29.08 \pm 1.71^{* *}$ & $10.24 \pm 0.67^{* *}$ \\
$0.47 \pm 0.09$ & $21.02 \pm 1.19$ & $5.28 \pm 0.37$
\end{tabular}

$\mathrm{p}<0.01$ versus HCG

Polyphenols, especially hydroxycinnamic acid derivatives, are widely distributed in plants [34,35]. These polyphenols are powerful antioxidants and have been reported to demonstrate antibacterial and antiinflammatory [36]. A number of reports are shown that polyphenol-rich extracts from certain berries and tea are effective inhibitors of PL in vitro [21,37]. In addition, some of the studies show that ellagitannins, chlorogenic acid and caffeic acid have a good effect on lipase inhibition $[38,39]$. In this study, the effective inhibition caused by WP may be due to these polyphenol, which are present in polyphenol extracts.

As expected, the present study has confirmed that HFD can induce a great gain of body weight [40]. In this paper, the effect of WP on obesity was tested using mice fed a high-fat diet containing $200 \mu \mathrm{g} / \mathrm{g}$ of WP. WP prevented the HFD-induced increase in body weight. This effect did not depend on decreased food because there were no significant differences among three groups. Evidence from pre-clinical and some clinical studies indicated that admistration of green tea containing caffeine [41] and vegetable such as rutgers scarlet lettuce with chlorogenic acid [42] resulted in lower body weight. In addition, some researchers have found a possible mechanism that protective effect against HFD-induced obesity in mice through an enhanced expression of uncoupling proteins and elevated AMPK phosphorylation in the visceral adipose tissue [43]. However, In this experiment, the data showed that supplement of WP can effectively inhibit weight gain, but the specific impact of WP on the development of obesity is still unknown and further investigation is needed.

These results suggest that WP have an antiobesity function: it prevents the hydrolysis of dietary fat in the small intestine and decreases the subsequent intestinal absorption of dietary fat. The hypolipidemic effects of WP showed in this study were similar with previous reports on mice fed a HFD [44,45]. Administration of WP reduced lipid contents in mice fed a HFD for 8 weeks. These results suggested that inhibition of intestinal lipid absorption was involved in the decrease of lipid contents, particularly triglyceride content.

\section{5. conclusion}

This experiment demonstrated that WP efficiently inhibited in vitro porcine PL activity. Additionally, it also showed that the treatment had powerful antiobesity activity on HFD-induced obese mice. Collectively, our results provided an important basis on the prevention and treatment of obesity. 


\section{Acknowledgments}

We gratefully acknowledged financial support of the National Natural Science Foundation of China (Grant No. 21466037), Supporting Plan Issue of the Ministry of Science and Technology (2011BAD46B00) and the science and technology major program of Yunnan education bureau (ZD2014009).

\section{Statement of Competing Interests}

None.

\section{List of Abbreviations}

WP: walnut polyphenols, HFD: high fat diet, PL: pancreatic lipase, TC: total cholesterol, TG: total triglycerides, LDL-C: LDL-cholesterol, HDL-C: HDLcholesterol, NCG: normol control group, HCG: hypercholesterolemia control group, WTG: walnut polyphenol-treated group, pNP laurate: p-nitrophenyl laurate.

\section{References}

[1] Pataky, Z., Bobbioni-Harsch, E., Hadengue, A., Carpentier, A., \& Golay, A., [Gut microbiota, responsible for our body weight?]. Revue medicale suisse, 5 (196), 662-4, 2009.

[2] Nakai, M., Fukui, Y., Asami, S., Toyoda-Ono, Y., Iwashita, T. Shibata, H., Kiso, Y., Inhibitory effects of oolong tea polyphenols on pancreatic lipase in vitro. Journal of Agricultural and Food Chemistry, 53 (11), 4593-4598, 2005.

[3] Yun, J.W., Possible anti-obesity therapeutics from nature-A review. Phytochemistry, 71 (14), 1625-1641, 2010.

[4] Zhang, J., Xiao, L., Yang, Y., Wang, Z., \& Li, G., Lignin binding to pancreatic lipase and its influence on enzymatic activity. Food chemistry, 149, 99-106, 2014.

[5] Birari, R.B., \& Bhutani, K.K., Pancreatic lipase inhibitors from natural sources: unexplored potential. Drug discovery today, 12 (19), 879-889, 2007.

[6] Thomson, A.B.R., De Pover, A., Keelan, M., Jarocka-Cyrta, E., \& Clandinin, M.T., Inhibition of lipid absorption as an approach to the treatment of obesity. Methods in enzymology, 286, 3-44, 1997.

[7] Garza, A.L., Milagro, F.I., Boque, N., Campión, J., \& Martinez, J. A., Natural inhibitors of pancreatic lipase as new players in obesity treatment, 77 (8), 773-785, 2011.

[8] Bhutani, K.K., Birari, R., \& Kapat, K., Potential anti-obesity and lipid lowering natural products: a review. Natural Product Communications, 2 (3), 331-348, 2007.

[9] Sumithran, P., \& Proietto, J., Benefit-Risk Assessment of Orlistat in the Treatment of Obesity. Drug Safety, 1-12, 2014.

[10] Kawaguchi, K., Mizuno, T., Aida, K., \& Uchino, K., Hesperidin as an inhibitor of lipases from porcine pancreas and Pseudomonas. Bioscience, biotechnology, and biochemistry, 61 (1), 102-104, 1997.

[11] Won, S.R., Kim, S.K., Kim, Y.M., Lee, P.H., Ryu, J.H., Kim, J.W., \& Rhee, H.I., Licochalcone A: A lipase inhibitor from the roots of Glycyrrhiza uralensis, Food research international, 40 (8), 10461050, 2007.

[12] Rastmanesh, R., High polyphenol, low probiotic diet for weight loss because of intestinal microbiota interaction. Chemicobiological interactions, 189 (1), 1-8, 2011.

[13] Schaefer, S., Baum, M., Eisenbrand, G., Dietrich, H., Will, F., \& Janzowski, C., Polyphenolic apple juice extracts and their major constituents reduce oxidative damage in human colon cell lines. Molecular nutrition \& food research, 50 (1), 24-33, 2006.

[14] McDougall, G.J., \& Stewart, D., The inhibitory effects of berry polyphenols on digestive enzymes. Biofactors, 23 (4), 189-195, 2005.
[15] Sakulnarmrat, K., Srzednicki, G., \& Konczak, I., Composition and inhibitory activities towards digestive enzymes of polyphenolicrich fractions of Davidson's plum and quandong. LWT-Food Science and Technology, 57 (1), 366-375, 2014.

[16] Wang, S., Dong, S., Zhang, R., Shao, H., \& Liu, Y., Effects of proanthocyanidins on porcine pancreatic lipase: Conformation, activity, kinetics and thermodynamics. Process Biochemistry, 49 (2), 237-243, 2014.

[17] Meydani, M., \& Hasan, S.T., Dietary polyphenols and obesity. Nutrients, 2 (7), 737-751, 2010.

[18] Ainsworth, E.A., \& Gillespie, K.M., Estimation of total phenolic content and other oxidation substrates in plant tissues using FolinCiocalteu reagent. Nature protocols, 2 (4), 875-877, 2007.

[19] Regueiro, J., Sánchez-González, C., Vallverdú-Queralt, A., SimalGándara, J., Lamuela-Raventós, R., \& Izquierdo-Pulido, M., Comprehensive identification of walnut polyphenols by liquid chromatography coupled to linear ion trap-Orbitrap mass spectrometry. Food chemistry, 152, 340-348, 2014.

[20] Ojha, H., Mishra, K., Hassan, M.I., \& Chaudhury, N.K., Spectroscopic and isothermal titration calorimetry studies of binding interaction of ferulic acid with bovine serum albumin. Thermochimica Acta, 548, 56-64, 2012.

[21] McDougall, G.J., Kulkarni, N.N., \& Stewart, D., Berry polyphenols inhibit pancreatic lipase activity in vitro. Food Chemistry, 115 (1), 193-199, 2009.

[22] Martins, F., Noso, T.M., Porto, V.B., Curiel, A., Gambero, A., Bastos, D.H., \& Carvalho, P.D.O., Maté Tea Inhibits In Vitro Pancreatic Lipase Activity and Has Hypolipidemic Effect on High-fat Diet-induced Obese Mice. Obesity, 18 (1), 42-47, 2010.

[23] Shaodong, C., Haihong, Z., Manting, L., Guohui, L., Zhengxiao, Z., \& Zhang, Y.M., Research of influence and mechanism of combining exercise with diet control on a model of lipid metabolism rat induced by high fat diet. Lipids Health Dis, 12, 21, 2013.

[24] Honda, H., Ikejima, K., Hirose, M., Yoshikawa, M., Lang, T., Enomoto, N., \& Sato, N., Leptin is required for fibrogenic responses induced by thioacetamide in the murine liver. Hepatology, 36 (1), 12-21, 2002.

[25] Yuan, H., Song, J., Li, X., Li, N., \& Dai, J., Immunomodulation and antitumor activity of $\kappa$-carrageenan oligosaccharides. Cancer letters, 243 (2), 228-234, 2006.

[26] Harnafi, H., Ramchoun, M., Tits, M., Wauters, J.N., Frederich, M., Angenot, L., \& Amrani, S., Phenolic acid-rich extract of sweet basil restores cholesterol and triglycerides metabolism in high fat diet-fed mice: A comparison with fenofibrate. Biomedicine \& Preventive Nutrition, 3 (4), 393-397, 2013.

[27] Shimoda, H., Tanaka, J., Kikuchi, M., Fukuda, T., Ito, H., Hatano, T., \& Yoshida, T., Effect of polyphenol-rich extract from walnut on diet-induced hypertriglyceridemia in mice via enhancement of fatty acid oxidation in the liver. Journal of agricultural and food chemistry, 57 (5), 1786-1792, 2009.

[28] Jang, D.S., Lee, G.Y., Kim, J., Lee, Y.M., Kim, J.M., Kim, Y.S., \& Kim, J.S., A new pancreatic lipase inhibitor isolated from the roots of Actinidia arguta. Archives of pharmacal research, 31 (5), 666-670, 2008.

[29] Lakowicz, J.R., \& Masters, B.R., Principles of fluorescence spectroscopy. Journal of Biomedical Optics, 13(2), 9901, 2008.

[30] Wu, X., He, W., Zhang, H., Li, Y., Liu, Z., \& He, Z., Acteoside: A lipase inhibitor from the Chinese tea Ligustrum purpurascens kudingcha. Food chemistry, 142, 306-310, 2014.

[31] Stojadinovic, M., Radosavljevic, J., Ognjenovic, J., Vesic, J., Prodic, I., Stanic-Vucinic, D., \& Cirkovic Velickovic, T., Binding affinity between dietary polyphenols and $\beta$-lactoglobulin negatively correlates with the protein susceptibility to digestion and total antioxidant activity of complexes formed. Food chemistry, 136 (3), 1263-1271, 2013.

[32] Augustin, M.A., Sanguansri, L., \& Lockett, T., Nano-and microencapsulated systems for enhancing the delivery of resveratrol. Annals of the New York Academy of Sciences, 1290 (1), 107-112, 2013.

[33] Tayeh, N., Rungassamy, T., \& Albani, J.R., Fluorescence spectral resolution of tryptophan residues in bovine and human serum albumins. Journal of pharmaceutical and biomedical analysis, 50 (2), 107-116, 2009.

[34] Herrmann, K., \& Nagel, C.W., Occurrence and content of hydroxycinnamic and hydroxybenzoic acid compounds in foods. Critical Reviews in Food Science \& Nutrition, 28 (4), 315-347, 1989. 
[35] Ignat, I., Volf, I., \& Popa, V.I., A critical review of methods for characterisation of polyphenolic compounds in fruits and vegetables. Food Chemistry, 126 (4), 1821-1835, 2011.

[36] Moreno, S., Scheyer, T., Romano, C.S., \& Vojnov, A.A., Antioxidant and antimicrobial activities of rosemary extracts linked to their polyphenol composition. Free radical research, 40 (2), 223-231, 2006

[37] Nakai, M., Fukui, Y., Asami, S., Toyoda-Ono, Y., Iwashita, T., Shibata, H., \& Kiso, Y., Inhibitory effects of oolong tea polyphenols on pancreatic lipase in vitro. Journal of Agricultural and Food Chemistry, 53 (11), 4593-4598, 2005.

[38] Määttä-Riihinen, K.R., Kamal-Eldin, A., Mattila, P.H., GonzálezParamás, A.M., \& Törrönen, A.R., Distribution and contents of phenolic compounds in eighteen Scandinavian berry species. Journal of Agricultural and Food Chemistry, 52 (14), 4477-4486, 2004.

[39] Raghavendra, M.P., Kumar, P.R., \& Prakash, V., Mechanism of inhibition of rice bran lipase by polyphenols: a case study with chlorogenic acid and caffeic acid. Journal of food science, 72(8), E412-E419, 2007.

[40] Wu, T., Qi, X., Liu, Y., Guo, J., Zhu, R., Chen, W., \& Yu, T., Dietary supplementation with purified mulberry (Morus australis
Poir) anthocyanins suppresses body weight gain in high-fat diet fed C57BL/6 mice. Food chemistry, 141 (1), 482-487, 2013.

[41] Westerterp-Plantenga, M.S., Lejeune, M.P., \& Kovacs, E.M. Body weight loss and weight maintenance in relation to habitual caffeine intake and green tea supplementation. Obesity research, 13 (7), 1195-1204, 2005.

[42] Cho, A.S., Jeon, S.M., Kim, M.J., Yeo, J., Seo, K.I., Choi, M.S., \& Lee, M.K., Chlorogenic acid exhibits anti-obesity property and improves lipid metabolism in high-fat diet-induced-obese mice. Food and Chemical Toxicology, 48 (3), 937-943, 2010.

[43] Pang, J., Choi, Y., \& Park, T., Ilex paraguariensis extract ameliorates obesity induced by high-fat diet: Potential role of AMPK in the visceral adipose tissue. Archives of biochemistry and biophysics, 476 (2), 178-185, 2008.

[44] Wu, C.H., Yang, M.Y., Chan, K.C., Chung, P.J., Ou, T.T., \& Wang, C.J., Improvement in high-fat diet-induced obesity and body fat accumulation by a Nelumbo nucifera leaf flavonoid-rich extract in mice. Journal of agricultural and food chemistry, 58 (11), 7075-7081, 2010

[45] Shi, D., Chen, C., Zhao, S., Ge, F., Liu, D., \& Song, H., Effects of Walnut Polyphenol on Learning and Memory Functions in Hypercholesterolemia Mice. Journal of Food and Nutrition Research, 2 (8), 450-456, 2014. 